\title{
Electrokinetic Properties of Nanosized SiC Particles in Highly Concentrated Electrolyte Solutions
}

\author{
Sheng-Chang Wang and Wen-Cheng J. Wei ${ }^{\star, \dagger}$ \\ Institute of Materials Science and Engineering, National Taiwan University, Taipei, Taiwan 106, Republic of China
}

In this research, the electrokinetic behavior and stability of nanosized $\mathrm{SiC}$ particles suspended in various electroplating solutions were studied. Analyses were performed using electrophoretic mobility photometry and streaming current (SC) techniques. The electrolytes included $\mathrm{NiCl}_{2}, \mathrm{Ni}\left(\mathrm{SO}_{3} \mathrm{NH}_{2}\right)_{2}$, and $\mathrm{Na}_{3} \mathrm{Co}\left(\mathrm{NO}_{2}\right)_{6}$, which are currently used in composite plating solutions with concentrations as high as $0.5 M$. The results showed that the adsorption of dissolved $\mathrm{Ni}^{2+}$ ions onto the surface of the $\mathrm{SiC}$ in the $\mathrm{pH}$ range 4-8 changed the sign and magnitude of the surface potential. Moreover, trivalent complex species $\mathrm{Co}\left(\mathrm{NO}_{2}\right)_{6}^{3-}$ replaced nickel species on the $\mathrm{SiC}$ surface and decreased the surface charge of SiC to between pH 3 and pH 5. Even in a highly concentrated electrolyte solution, the $\mathrm{SiC}$ particles still maintained a positive charge in a $\mathrm{Ni}\left(\mathrm{SO}_{3} \mathrm{NH}_{2}\right)_{2}$ suspension with nickel coplating on the cathode. The difference between the SC reading and the zeta potential, as well as the surface adsorption of various species onto the $\mathrm{SiC}$, are discussed here.

\section{Introduction}

$\mathrm{C}$ OLLOIDAL processing of nanosized $\mathrm{SiC}$ powder (particle size $<100 \mathrm{~nm}$ ) recently has received increasing attention because it provides various advantages, such as low-temperature sintering, mechanical-property improvement, and high-temperature superplasticity. ${ }^{1-3}$ When nanosized $\mathrm{SiC}$ particles are dispersed in a metallic matrix prepared by composite plating, the wear resistance of the $\mathrm{SiC} /$ nickel composite improves $\sim 50$ times over that of a pure nickel sample after heat treatment at $400^{\circ} \mathrm{C} .{ }^{4}$ However, agglomeration often occurs in these ultrafine powders with high specific surface areas during powder processing, leading to various defects in the green and sintered ceramics. These defects are the major reasons for inhomogeneous microstructures, low density, and poor mechanical properties.

In an aqueous or nonaqueous colloidal system, dispersion of these ultrafine powders is one of the key steps toward achieving optimal mechanical properties for composites prepared by slip casting, electrophoretic deposition, or composite electroplating. The stability of nanoparticles in suspension is controlled by the colloidal properties, e.g., the thickness of the double layer and the zeta potential of the fine particles. According to the Deryagin, Landau, Verwey, and Overbeek (DLVO) theory, ${ }^{5}$ the van der Waals attractive force and the electrostatic repulsive force are two important interaction forces dominating in an aqueous suspension

L. Bergstrom—contributing editor

\footnotetext{
Manuscript No. 188439. Received June 26, 2000; approved February 22, 2001 Supported by the National Science Council of Taiwan, under Contact No. NSC89-2216-E-002-016.

${ }^{*}$ Member, American Ceramic Society.

*Member, American Ceramic Society.
${ }^{*}$ Author to whom correspondence should be addressed: Institute of Materials Science and Engineering, National Taiwan University, 1 Roosevelt Rd., Section 4, Taipei, Taiwan 106, ROC.
}

system. If the surface charge of the powders is sufficiently high, a well-dispersed suspension is obtained.

Wang and $\mathrm{Wei}^{6}$ showed that the addition of polyethylenimine (PEI) could disperse submicrometer $\mathrm{SiC}$ powder in an aqueous or alcoholic solution. PEI increased the $\mathrm{pH}$ of the suspension, and the adsorption of PEI onto $\mathrm{SiC}$ reversed the surface charge of the $\mathrm{SiC}$ from negative to positive. Therefore, the isoelectric point (IEP) of the $\mathrm{SiC}$ powders shifted from $\mathrm{pH} 3.2$ to $\mathrm{pH} 10.1$ in the solution with dissolved PEI. A similar attempt was made by Iskra $^{7}$ who used various ionic compounds to float coarse $\mathrm{SiC}$ powder with particle sizes of 75-150 $\mu \mathrm{m}$. Iskra found that cationic dodecylammonium chloride could be adsorbed onto the surfaces of the $\mathrm{SiC}$ particles, leading to an IEP change from $\mathrm{pH} 2.8$ to $\mathrm{pH} 10$.

The IEPs of $\mathrm{SiC}$ reported in the literature range from $\mathrm{pH} 2$ to $\mathrm{pH} \mathrm{3}$, similar to that of $\mathrm{SiO}_{2} .{ }^{8}$ A possible explanation for this similarity may be the presence of a thin $\mathrm{SiO}_{2}$ layer on $\mathrm{SiC}$. If the free $\mathrm{SiO}_{2}$ layer is leached by $\mathrm{HF}$, the IEP of pure $\mathrm{SiC}$ particles increases to $\mathrm{pH} 6$, and the stability of the $\mathrm{SiC}$ suspension decreases, because of the presence of a native hydrophobic layer. ${ }^{9}$ An increase in the stability of the $\mathrm{SiC}$ suspension, caused by the increase in the thickness of the hydrophilic amorphous $\mathrm{SiO}_{2}$ layer by heat treating at $650^{\circ} \mathrm{C}$, also is documented.

Streaming current (SC) is one of the techniques used for measuring the electrokinetic properties of particles in solution. ${ }^{10,11}$ The SC method is capable of monitoring electrokinetic properties of the particles on line in a highly concentrated electrolyte and/or a highsolids-content solution. In a previous investigation, ${ }^{12}$ we measured the $\mathrm{SC}$ of $\mathrm{ZrO}_{2}$ suspensions with different solids contents or electrolytes. Those results showed that the $\mathrm{SC}$ reading and zeta potential of a $\mathrm{ZrO}_{2}$ suspension fit a linear correlation. Therefore, the SC method can replace electrophoretic mobility photometry (EMP) for measuring the electrokinetic properties of a ceramic suspension.

To produce a well-dispersed composite layer during the composite plating of ultrafine ceramic particles with metal, the particles in the plating suspension must have a positive surface charge and must not agglomerate. In this study, we investigated the surface charging and dispersive behaviors of ultrafine $\mathrm{SiC}$ in solutions that contained nickel sulfamate $\left(\mathrm{Ni}\left(\mathrm{SO}_{3} \mathrm{NH}_{2}\right)_{2}\right)$, nickel chloride $\left(\mathrm{NiCl}_{2}\right)$, and other chemical species. Because of the high ionic strength and solids loadings of the $\mathrm{SiC}$ suspensions used in the electroplating, the surface properties of the plating suspensions were beyond the measurement capabilities of EMP. Therefore, the SC technique was chosen in the present study to investigate various $\mathrm{SiC}$ suspensions.

\section{Experimental Procedure}

A plasma-synthesized $\mathrm{SiC}$ powder (PJ-PL-SiC, PlasmaChem $\mathrm{GmbH}$, Mainz, Germany) of ultrafine particle size was used in this study. The particle size was measured by a particle-size analyzer, based on the laser light-scattering technique (Mastersizer 2000, Malvern Instruments, Ltd., Malvern, U.K.), and transmission electron microscopy (TEM; Model 100CXII, JEOL, Tokyo, Japan). For the analysis of particle size, a suspension containing 2 vol\% of PEI (Scientific Polymer Products, Inc., Ontario, NY) was ultrasonicated for $30 \mathrm{~min}$, to decrease agglomeration. The chemical formula and mean molecular weight $\left(M_{\mathrm{w}}\right)$ of the PEI were $\left(\mathrm{CH}_{2} \mathrm{CH}_{2} \mathrm{NH}\right)_{n}$ and $\sim 5000 \mathrm{~g} / \mathrm{mol}$, respectively. 
Diluted suspensions with deionized water $(\Omega>15$ Mohm-cm) were prepared with various solids loadings. The $\mathrm{pH}$ of the suspensions was adjusted by a reagent-grade $0.1 M \mathrm{HCl}$ or $\mathrm{NaOH}$ solution. The electrolytes $\mathrm{Ni}\left(\mathrm{SO}_{3} \mathrm{NH}_{2}\right)_{2}$ (Phibrochem, Inc., Fort Lee, $\mathrm{NJ}), \mathrm{NiCl}_{2}$ (EP grade, Showa Denko, K.K., Tokyo, Japan) or sodium hexanitrocobaltate $\left(\left(\mathrm{Na}_{3} \mathrm{Co}\left(\mathrm{NO}_{2}\right)_{6}\right)\right.$, Jassen Chimica, Beerse, Belgium) were used. Suspensions with these electrolytes were exposed to an ultrasonic probe (Model RK103, Sonorex, Taiwan, R.O.C.) at $35 \mathrm{kHz}$ and $150 \mathrm{~W}$, for $10 \mathrm{~min}$, and the $\mathrm{pH}$ values before and after electrokinetic measurement were recorded, for studying reactions within the suspension. The temperature of all of the suspensions was kept constant at $25^{\circ} \pm 1^{\circ} \mathrm{C}$. Unless specified in the text, $0.01 M \mathrm{NaCl}$ (reagent grade, Nacalai Tesque, Inc., Kyoto, Japan) was added to the suspensions, to maintain the same ionic strength as before addition of the powders.

The microstructures and phases of the powders were observed by TEM, high-resolution TEM (HRTEM; Model 400FX, JEOL) and X-ray diffractometry (XRD; Model PW1792, Philips Research Laboratories, Eindhoven, The Netherlands). An electrophoretic mobility meter (Laser Zee 501, Pen Ken, Inc., Bedford Hills, NY) and an electrokinetics charge analyzer (Model ECA2000, Chemtrac Systems, Inc., Norcross, GA) were used to measure the zeta potential and SC, respectively. During measurement of the electrophoretic mobility, larger particles $(\geq 0.1 \mu \mathrm{m})$ were easier to observe than small particles $(\sim 20 \mathrm{~nm}$ ) by optical microscopy. Thus, the assumptions made for the Smoluchowski equation were effective for estimating the zeta potential of the larger $\mathrm{SiC}$ particles, but a 5\%-20\% variation of the surface potential was possible for the smaller particles.

\section{Results and Discussion}

\section{(1) Characterization of the SiC Powder}

The morphology of the ultrafine $\mathrm{SiC}$ powder observed by TEM is shown in Fig. 1(a). The SiC was angular in shape for nanosized particles and nearly triangular for some submicrometer-sized particles. The particle-size distribution was close to a Gaussian distribution, as shown in Fig. 1(b). The mean particle size of the as-received powder was $62 \mathrm{~nm}$. HRTEM study of the surface revealed that the $\mathrm{SiC}$ was surrounded by a thin, amorphous $\mathrm{SiO}_{2}$ layer 2-5 $\mathrm{nm}$ thick. According to thermogravimetric (TGA) analysis, the $\mathrm{SiC}$ powder did not oxidize before $350^{\circ} \mathrm{C}$.

\section{(2) Streaming Current and Zeta Potential of the SiC}

The SC reading and zeta potential of the $\mathrm{SiC}$ particles in the $0.01 M \mathrm{NaCl}$ electrolyte are shown in Fig. 2. These two curves show a similar trend, but the points of zero value (either potential or current) measured by the two methods are different. The IEP and isocurrent point (ICP) of the $\mathrm{SiC}$ are $\mathrm{pH} 2.6$ and $\mathrm{pH} 3.0$, respectively. These result are very close to the IEP value of $\mathrm{SiO}_{2}$ reported previously. ${ }^{8}$

From the result of Fig. 2, the relationship between the SC reading (I) and the zeta potential ( $\zeta$ ) is plotted in Fig. 3. As the curves depict, these data points can be fitted as either a linear function or a polynomial function of the second order. A shift from the zero point occurs. Zero potential is found at a streaming current of $0.18 \mathrm{~mA}$.

The offset is a result of the positive charge on the surface of the capillary passage in the SC detector. The surface charge of the SiC particles was nearly neutral when the suspension was strongly acidic ( $\mathrm{pH}$ 2.5-3.5). With no electric repulsive force, the van der Waals force between the particles dominated the surface forces, and the particles tended to aggregate. As shown in Fig. 4, the SC reading of the polytetrafluoroethylene (PTFE) was $0.3 \mathrm{~mA}$ at $\mathrm{pH}$ 2.6. The PTFE detector contributed a positive charge to the $\mathrm{SC}$ reading.

\section{(3) Influence of the Electrolyte}

$\mathrm{NiCl}_{2}$ is added to a sulfamate plating solution to decrease polarization of the anode during electroplating. Figure 5 shows the zeta potential and $\mathrm{SC}$ readings of dilute $\mathrm{SiC}$ suspensions $(0.01 \mathrm{vol} \%)$ with $\mathrm{NiCl}_{2}$ as the electrolyte. The zeta potential of the $\mathrm{SiC}$ surfaces changed polarity from negative to positive at $\mathrm{pH}$
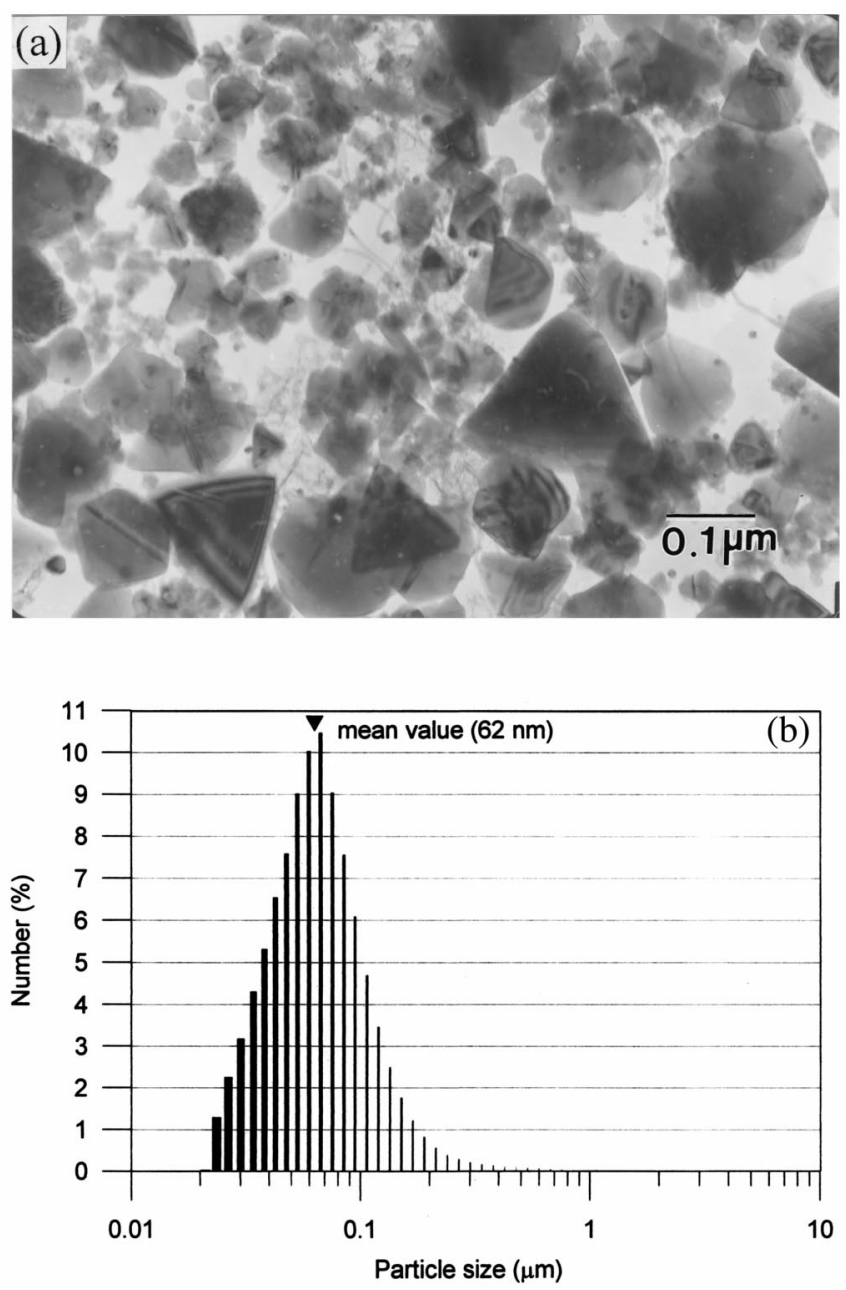

Fig. 1. (a) Transmission electron micrograph of nanosized $\mathrm{SiC}$ and (b) particle-size distribution of $\mathrm{SiC}$; mean particle size is $62 \mathrm{~nm}$, and $2 \mathrm{vol} \%$ of PEI dispersant was added.

values $>4$ and reached a maximum at $\mathrm{pH} 7$. When the $\mathrm{pH}$ value was $>7$, the $\mathrm{Ni}^{2+}$ ions tended to form a hydrate $\mathrm{Ni}(\mathrm{OH})_{2}$ precipitate, and the zeta potential of the $\mathrm{SiC}$ decreased (Fig. 5(a)). The trend of zeta potential change in the suspensions was similar at various concentrations of $\mathrm{NiCl}_{2}$. Even a trace amount, $10^{-6} \mathrm{M}$,

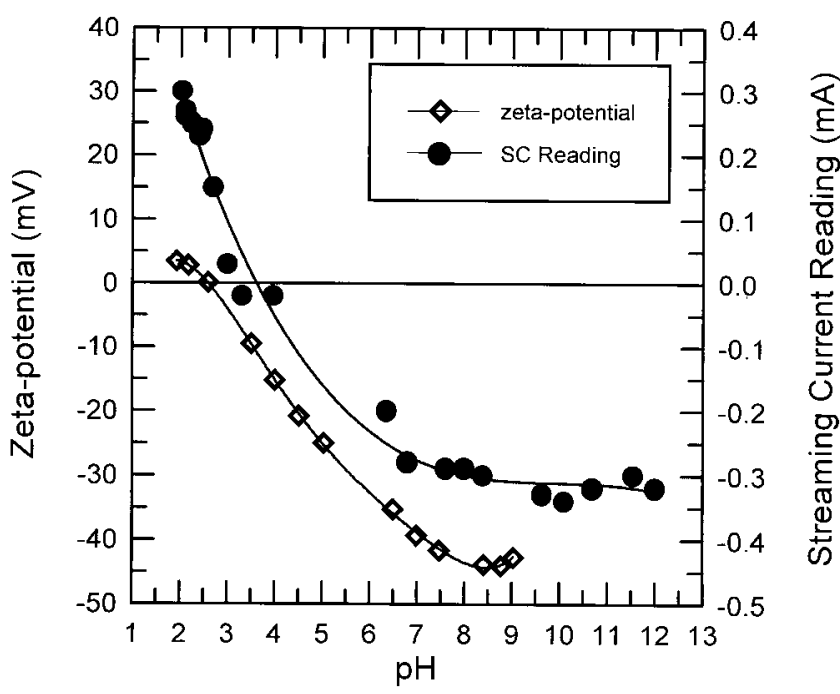

Fig. 2. Variation of zeta potential and $\mathrm{SC}$ readings of $\mathrm{SiC}$ with $\mathrm{pH}$ in diluted suspension (0.01 vol\% particle loading). 


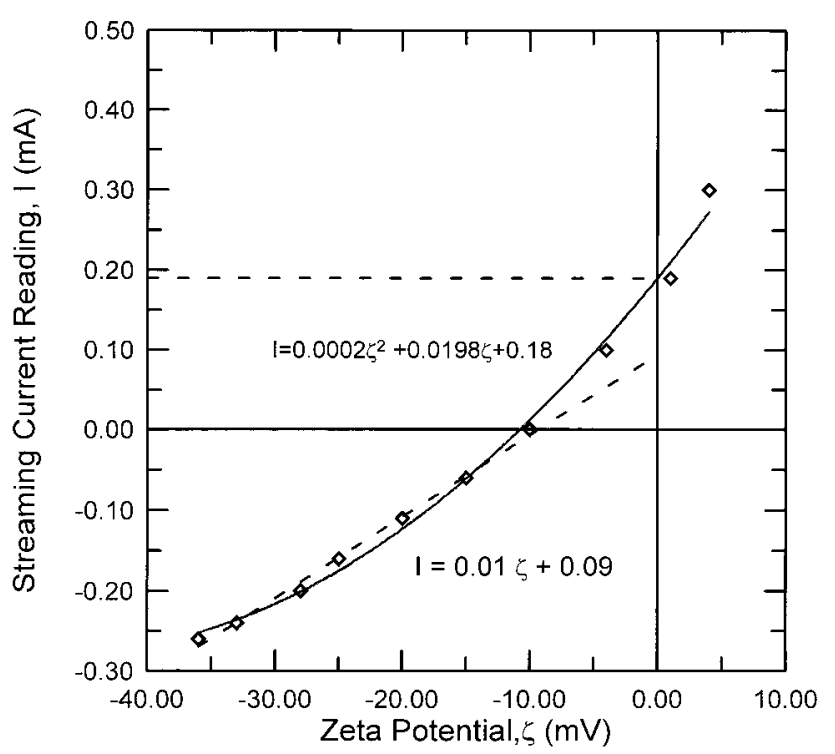

Fig. 3. Zeta potential plotted versus $\mathrm{SC}$ reading for $\mathrm{SiC}$ powder. Zero value of zeta potential equals the $\mathrm{SC}$ reading at $0.18 \mathrm{~mA}$ for the suspension with $0.01 \mathrm{vol} \%$ particle content.

of $\mathrm{NiCl}_{2}$ changed the surface potential. In the same way, the SC readings (Fig. 5(b)) show a trend parallel with that for the zeta potential. However, the values of the $\mathrm{SC}$ reading decreased somewhat when the concentration of $\mathrm{NiCl}_{2}$ was $0.023 \mathrm{M}$.

The surface charge changed from negative to positive in the $\mathrm{pH}$ range 4-6 when $\mathrm{NiCl}_{2}$ was added. This result suggests that adsorption of the divalent ion $\mathrm{Ni}^{2+}$ onto the particle surface is possible. The adsorption equilibrium can be written as follows:

$$
-\mathrm{Si}-\mathrm{O}^{-}+\mathrm{Ni}^{2+}=-\mathrm{Si}-\mathrm{O}-\mathrm{Ni}^{+}
$$

The solubility product $\left(K_{\mathrm{sp}}\right)$ of $\mathrm{Ni}(\mathrm{OH})_{2}$ at $25^{\circ} \mathrm{C}$ is $3 \times 10^{-16} .^{13}$ When the concentration of $\mathrm{Ni}^{2+}$ is $0.023 \mathrm{M}$ and the $\mathrm{pH}$ value is $>7.1, \mathrm{Ni}(\mathrm{OH})_{2(s)}$ is oversaturated and begins to precipitate. When $\mathrm{Ni}(\mathrm{OH})_{2}$ precipitation occurs on the heterogeneous $\mathrm{SiC}$ surface, the $\mathrm{Ni}^{2+}$ charge on the surface of the $\mathrm{SiC}$ is neutralized, thus reducing the surface charge. Consequently, some $\mathrm{SiC}$ agglomerates form in the weakly basic solution. In similar cases, $\mathrm{Mg}^{2+}$ or

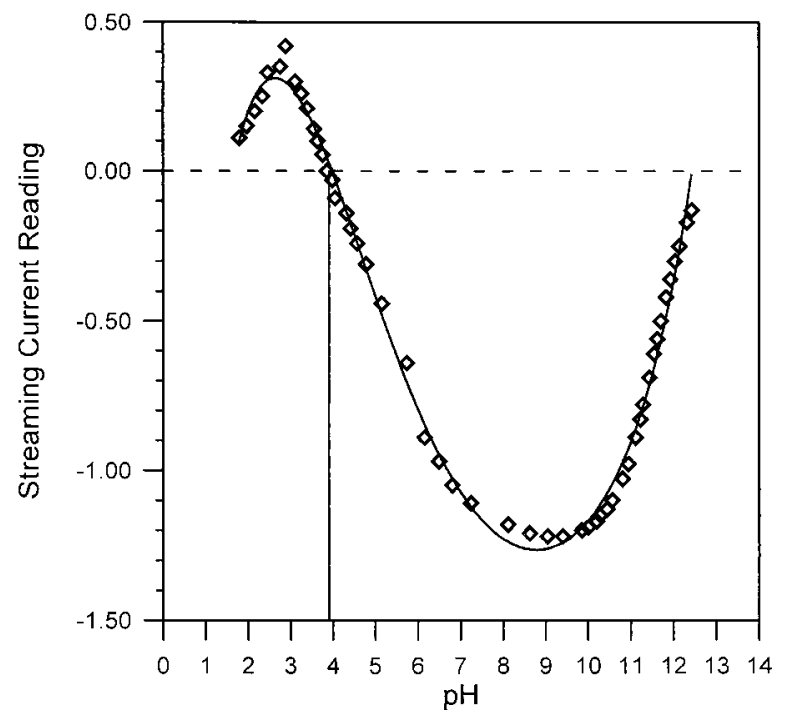

Fig. 4. Variation of SC of the SC detector made by PTFE plotted versus $\mathrm{pH}$. Solution contains $0.01 \mathrm{M} \mathrm{NaCl}$ as the electrolyte and no added $\mathrm{SiC}$ particles.
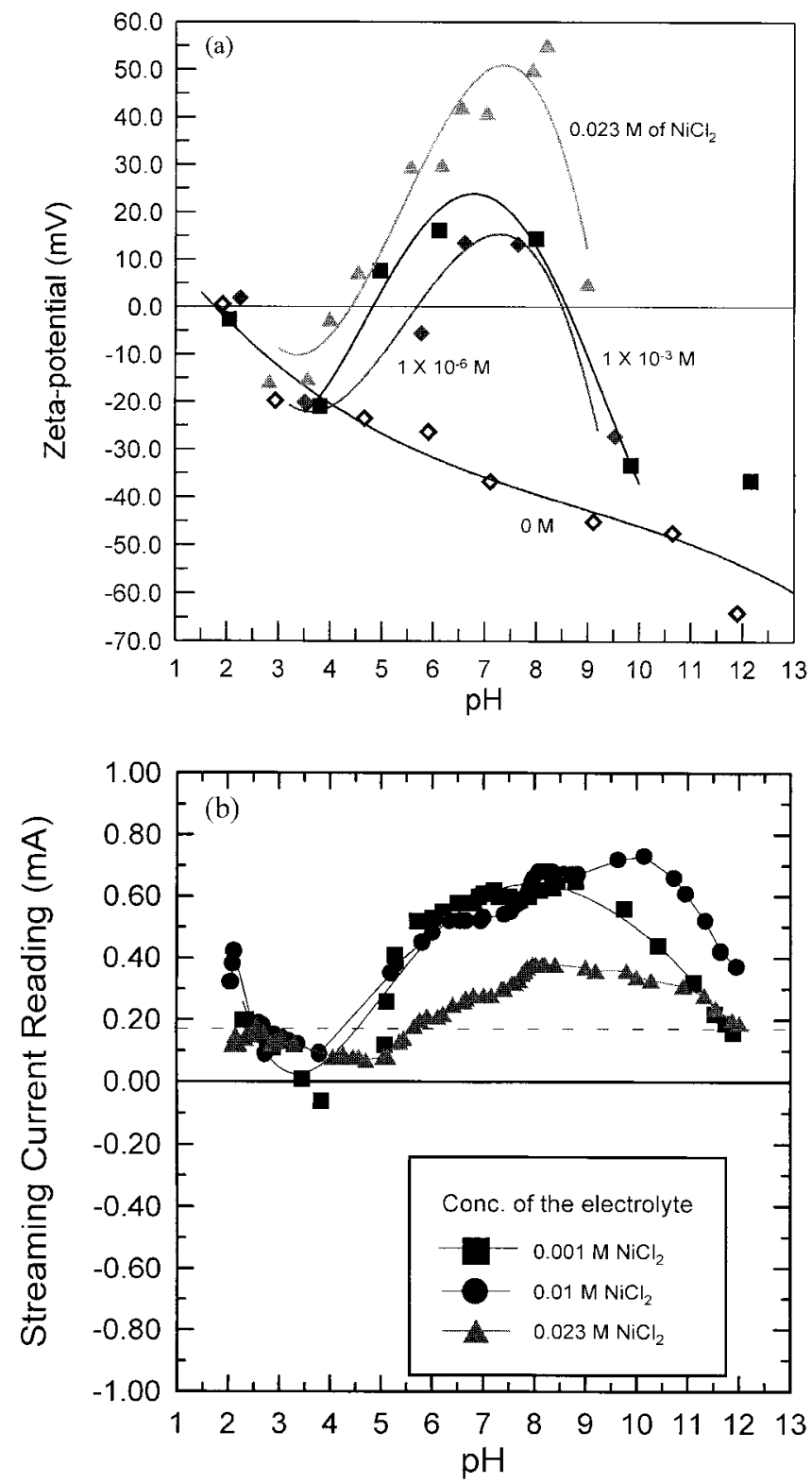

Fig. 5. (a) Zeta potential and (b) SC reading of $\mathrm{SiC}$ suspensions, as a function of different concentrations of $\mathrm{NiCl}_{2}$.

$\mathrm{Mg}(\mathrm{OH})^{+}$adsorbed onto the $\mathrm{SiC}$ particle surface have been reported, ${ }^{14}$ depending on the $\mathrm{pH}$ range. In a high $\mathrm{pH}$ range, $\mathrm{Mg}(\mathrm{OH})_{2(s)}$ also precipitates onto the surface of the particles.

$\mathrm{Ni}\left(\mathrm{SO}_{3} \mathrm{NH}_{2}\right)_{2}$ is the other important electrolyte for nickel electroplating. Similarly to $\mathrm{NiCl}_{2}, \mathrm{Ni}\left(\mathrm{SO}_{3} \mathrm{NH}_{2}\right)_{2}$ dissolves in an aqueous solution and contributes $\mathrm{Ni}^{2+}$ ions to the solution. Figure 6 shows that the zeta potential of $\mathrm{SiC}$ in the $\mathrm{Ni}\left(\mathrm{SO}_{3} \mathrm{NH}_{2}\right)_{2}$ electrolyte behaved similarly to that in the $\mathrm{NiCl}_{2}$ solution. When the $\mathrm{pH}$ value of the suspension was in the range $2-3$, the $\mathrm{SiC}$ particles had almost no surface potential. However, the potential increased, then decreased, as the $\mathrm{pH}$ of suspension changed from 4 to 8 .

\section{(4) Adsorption of Aliovalent Ions}

$\mathrm{Na}_{3} \mathrm{Co}\left(\mathrm{NO}_{2}\right)_{6}$ is one type of surfactant used in composite plating to modify the $\mathrm{SiC}$ solids content in the electroplated nickel layer. ${ }^{4}$ When $2 \mathrm{vol} \%$ of $\mathrm{Na}_{3} \mathrm{Co}\left(\mathrm{NO}_{2}\right)_{6}$ is added to $\mathrm{SiC}$ suspensions containing $\mathrm{Ni}\left(\mathrm{SO}_{3} \mathrm{NH}_{2}\right)_{2}$ as an electrolyte, the zeta potential of $\mathrm{SiC}$ gradually becomes negatively charged, for $\mathrm{pH} \geq 4$, as indicated by the broken lines in Fig. 6. $\mathrm{Na}_{3} \mathrm{Co}\left(\mathrm{NO}_{2}\right)_{6}$ readily dissolves in water. The cation $\mathrm{Na}^{+}$and the anion $\mathrm{Co}\left(\mathrm{NO}_{2}\right)_{6}^{3-}$ form in the solution, similarly to the case for $\mathrm{Ni}\left(\mathrm{SO}_{3} \mathrm{NH}_{2}\right)_{2}$. However, $\mathrm{Ni}^{2+}$ ions are likely to interact with water molecules to form a complex ion, 


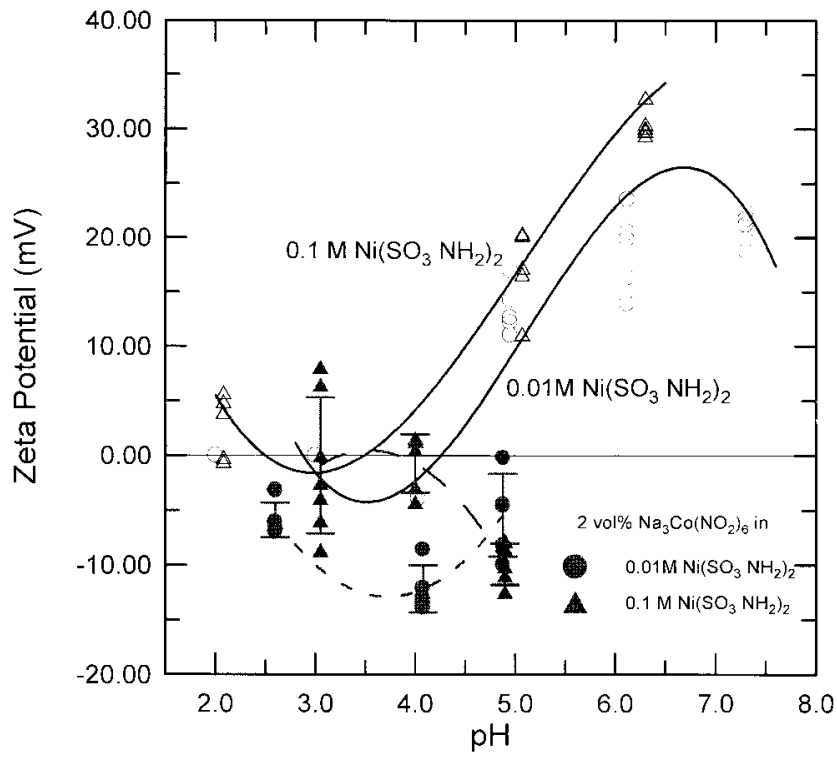

Fig. 6. Zeta potential of dilute $\mathrm{SiC}$ suspensions containing $\mathrm{Ni}\left(\mathrm{SO}_{3} \mathrm{NH}_{2}\right)_{2}$ as the electrolyte (open symbols) and 2 vol\% of $\mathrm{Na}_{3} \mathrm{Co}\left(\mathrm{NO}_{2}\right)_{6}$ (filled symbols).

$\mathrm{Ni}\left(\mathrm{H}_{2} \mathrm{O}\right)_{6}^{2+}$, in an aqueous solution. Two types of situation may occur: the negative anion $\mathrm{Co}\left(\mathrm{NO}_{2}\right)_{6}^{3-}$ may adsorb on top of the $\mathrm{Ni}^{2+}$ cations and neutralize the particle charge, or the adsorption of $\left(\mathrm{Co}\left(\mathrm{NO}_{2}\right)_{6}^{3-}\right.$ or $\mathrm{Ni}\left(\mathrm{H}_{2} \mathrm{O}\right)_{6}^{2+}$ onto $\mathrm{SiC}$ may be competitive. The $\mathrm{Co}\left(\mathrm{NO}_{2}\right)_{6}^{3-}$ ion has a stronger change intensity, defined as the ratio of valence to size of an ion, than that of $\mathrm{Ni}\left(\mathrm{H}_{2} \mathrm{O}\right)_{6}^{2+}$. Therefore, the decrease of the zeta potential of $\mathrm{SiC}$ can result from the adsorption of the anion $\mathrm{Co}\left(\mathrm{NO}_{2}\right)_{6}^{3-}$, which replaces the adsorbed $\mathrm{Ni}\left(\mathrm{H}_{2} \mathrm{O}\right)_{6}^{2+}$ and neutralizes the positive surface of the $\mathrm{SiC}$. Moreover, the $\mathrm{Co}\left(\mathrm{NO}_{2}\right)_{6}^{3-}$ in $\mathrm{pH}>4$ may reverse the surface charge of the $\mathrm{SiC}$ from positive to negative. That reverse makes the coplating of $\mathrm{SiC}$ with nickel ineffective. In the practical exercise of composite plating, the solution contains $1 \mathrm{vol} \%$ of $\mathrm{SiC}$ particles; $0.28 \mathrm{M}$ $\mathrm{Ni}\left(\mathrm{SO}_{3} \mathrm{NH}_{2}\right)_{2}$, as a source of $\mathrm{Ni}^{2+}$ ions; $0.023 \mathrm{M} \mathrm{NiCl}_{2}$; and $0.48 M$ $\mathrm{H}_{3} \mathrm{BO}_{3}$, as a buffer to keep the solution acidic, at $\mathrm{pH} 4$.

\section{(5) Electroplating of SiC with Nickel}

The $\mathrm{SC}$ readings of $\mathrm{SiC}$ in a series of suspensions with different concentrations of $\mathrm{Ni}\left(\mathrm{SO}_{3} \mathrm{NH}_{2}\right)_{2}$ solutions are shown in Fig. 7. All

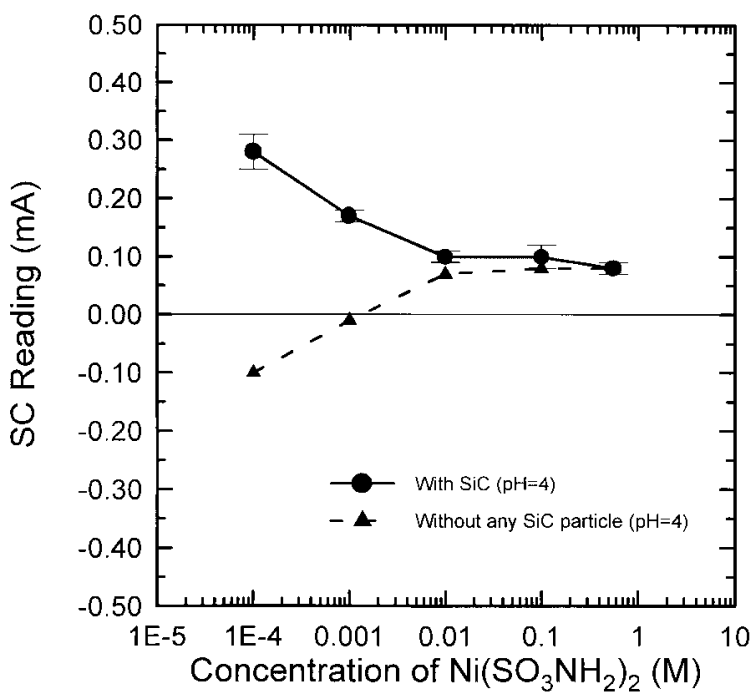

Fig. 7. SC readings of the electroplating solution with and without $\mathrm{SiC}$ particles, at various concentrations of $\mathrm{Ni}\left(\mathrm{SO}_{3} \mathrm{NH}_{2}\right)_{2}$. of the $\mathrm{Ni}\left(\mathrm{SO}_{3} \mathrm{NH}_{2}\right)_{2} / \mathrm{SiC}$ suspensions had $0.48 M \mathrm{H}_{3} \mathrm{BO}_{3}$ and $0.023 \mathrm{M} \mathrm{NiCl}_{2}$ added. The results consist of two sets of data. The set without $\mathrm{SiC}$, used as the control, reveals that the SC readings changed gently from -0.1 to $0.8 \mathrm{~mA}$ as the $\mathrm{Ni}^{2+}$ ion strength increased. When 1.0 vol\% of $\mathrm{SiC}$ was suspended in highly ionic solutions, the double-layer thickness of $\mathrm{SiC}$ was compressed, and the particles began to agglomerate. The contribution of $\mathrm{SiC}$ to the SC reading was insignificant, and the PTFE material of the capillary wall of the detector dominated the SC results.

In the high-concentration electrolyte solutions, the $\mathrm{SC}$ reading of the PTFE changed from negative in a dilute electrolyte to positive when the $\mathrm{Ni}\left(\mathrm{SO}_{3} \mathrm{NH}_{2}\right)_{2}$ concentration was $>0.001 M$. Those results illustrate that the PTFE surface also adsorbed $\mathrm{Ni}\left(\mathrm{H}_{2} \mathrm{O}\right)_{6}^{2+}$ ions. However, the net $\mathrm{SC}$ values $\left(\Delta \mathrm{SC}=\mathrm{SC}_{\mathrm{SiC}}-\mathrm{SC}_{\mathrm{PTFE}}\right)$ of the $\mathrm{SiC}$ suspensions were still positive for the concentration of $\mathrm{Ni}\left(\mathrm{SO}_{3} \mathrm{NH}_{2}\right)_{2}$ $<0.5 M$. These results imply that positive $\mathrm{SiC}$ particles can move to the cathode during composite electroplating.

\section{Conclusions}

The electrokinetic properties of nanosized SiC particles were measured by EMS and SC techniques, the latter of which are capable of operating in a suspension with a broader range of electrolyte concentrations and powder loadings. The IEP of the $\mathrm{SiC}$ suspension obtained by EMS was $\mathrm{pH} 2.6$, but the ICP for the $\mathrm{SC}$ technique was $\mathrm{pH} 3.0$. A $0.18 \mathrm{~mA}$ offset of the $\mathrm{SC}$ reading when the zeta potential was zero is attributed to the effect of the surface charge of the PTFE material on the SC detector at $\mathrm{pH} 2-3$.

In an aqueous solution containing $\mathrm{Ni}^{2+}$ ions, divalent ions are adsorbed onto the surface of the ultrafine $\mathrm{SiC}$ particles and change the polarity of the $\mathrm{SiC}$ from negative to positive, in the $\mathrm{pH}$ range 4-8. This phenomenon was found in the suspensions containing $\mathrm{NiCl}_{2}$ and/or $\mathrm{Ni}\left(\mathrm{SO}_{3} \mathrm{NH}_{2}\right)_{2}$ as electrolytes. However, $\mathrm{Ni}(\mathrm{OH})_{2}$ formed and precipitated in a basic solution when the $\mathrm{pH}$ values were $>7$. When trivalent ions, $\mathrm{Co}\left(\mathrm{NO}_{2}\right)_{6}^{3-}$, were added to the suspensions, the complex ions adsorbed onto the positive surface of the $\mathrm{SiC}$ and neutralized the surface charge, ultimately reversing the surface polarity of the SiC.

The surface-potential analysis results indicate that $\mathrm{SiC}$ particles can be suspended in a highly concentrated nickel electroplating solution. The surface charge of the $\mathrm{SiC}$ can adsorb $\mathrm{Ni}^{2+}$ ions and show a positively charged surface. A slightly positive surface charge is maintained as the concentration of $\mathrm{Ni}\left(\mathrm{SO}_{3} \mathrm{NH}_{2}\right)_{2}$ is increased to as high as $0.5 \mathrm{M}$.

\section{References}

${ }^{1}$ T. Sakka, D. D. Bidinger, and I. A. Aksay, "Processing of Silicon CarbideMullite-Alumina Nanocomposites," J. Am. Ceram. Soc., 78 [2] 479-86 (1995).

${ }^{2}$ R. Vassen and D. Stöver, "Processing and Properties of Nanograin Silicon Carbide," J. Am. Ceram. Soc., 82 [10] 2585-93 (1999).

${ }^{3}$ Y. Shinoda, T. Nagano, and H. Gu, "Superplasticity of Silicon Carbide," J. Am. Ceram. Soc., 82 [10] 2916-18 (1999).

${ }^{4}$ S. C. Wang, K. H. Shen, C. S. Lee, and W. J. Wei, "Composite Electro-Plating of Ni Layers with Ultra-Fine SiC Particles"; pp. 70-77 in Proceedings of the Relationship on Properties, Processing and Microstructure of Advanced Ceramics, 5th IUMRS (Beijing, China, 1999). Edited by J. Guo and X. Yao. Shanghai Scientific and Technology Literature, Beijing, China.

${ }^{5}$ R. J. Hunter, Foundations of Colloid Science, Vol. 1. Oxford University Press, Oxford, U.K., 1989.

${ }^{6}$ L. M. Wang and W. C. Wei, "Colloidal Processing and Liquid-Phase Sintering of SiC," J. Ceram. Soc. Jpn., 103 [5] 434-43 (1995).

${ }^{7}$ J. Iskra, "Flotation Properties of Silicon Carbide I. Flotation of Silicon Carbide with Anionic and Cationic Collector," Ceram. Int., 23, 337-42 (1997).

${ }^{8}$ J. S. Reed, Principles of Ceramics Processing, 2nd ed., Ch. 10. Wiley, New York, 1995.

${ }^{9} \mathrm{P}$. Tartaj, M. Reece, and J. S. Moya, "Electrokinetic Behavior and Stability of Silicon Carbide Nanoparticulate Dispersions," J. Am. Ceram. Soc., 81 [2] 389-94 (1998).

${ }^{10}$ S. K. Dentel, A. V. Thomas, and K. M. Kingery, "Evaluation of the Streaming Current Detector-I. Use in Jar Test," Water Res., 23 [4] 413-21 (1989).

${ }^{11}$ S. K. Dentel and K. M. Kingery, "Theoretical Principles of Streaming Current Detection," Water Sci. Technol., 21, 443-53 (1989).

${ }^{12}$ W. J. Wei, S. C. Wang, and F. Y. Ho, "Electrokinetic Properties of Colloidal Zirconia Powders in Aqueous Suspension," J. Am. Ceram. Soc., 82 [12] 3385-92 (1999).

${ }^{13}$ L. G. Sillen, Stability Constants of Metal-Ion Complexes, 2nd ed. Chemical Society, Burlington House, London, U.K., 1964.

${ }^{14}$ R. J. Pugh and L. Bergström, "The Uptake of $\mathrm{Mg}(\mathrm{II})$ on Ultrafine $\alpha$-Silicon Carbide and $\alpha$-Alumina," J. Colloid. Interface Sci., 124 [2] 570-80 (1988). 